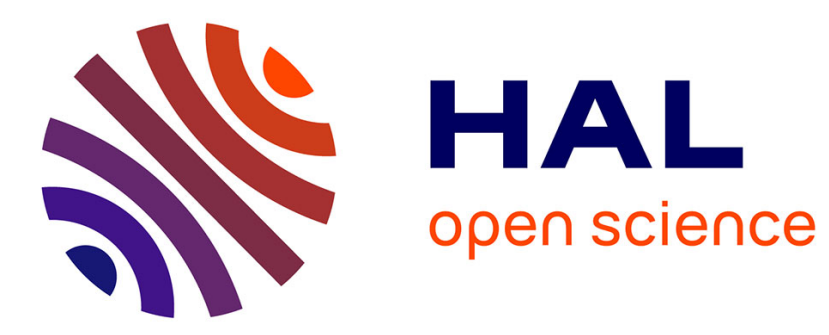

\title{
Designing a new two-dimensional molecular layout by hydrogen bonding
}

Mathieu Abel, Vincent Oison, Mathieu Koudia, C. Maurel, Claudine Katan, Louis Porte

\section{- To cite this version:}

Mathieu Abel, Vincent Oison, Mathieu Koudia, C. Maurel, Claudine Katan, et al.. Designing a new two-dimensional molecular layout by hydrogen bonding. ChemPhysChem, 2006, 7 (1), pp.82-85. 10.1002/cphc.200500334 . hal-00517124

\section{HAL Id: hal-00517124 \\ https://hal.science/hal-00517124}

Submitted on 15 Sep 2010

HAL is a multi-disciplinary open access archive for the deposit and dissemination of scientific research documents, whether they are published or not. The documents may come from teaching and research institutions in France or abroad, or from public or private research centers.
L'archive ouverte pluridisciplinaire HAL, est destinée au dépôt et à la diffusion de documents scientifiques de niveau recherche, publiés ou non, émanant des établissements d'enseignement et de recherche français ou étrangers, des laboratoires publics ou privés. 
communication

\section{Designing New Two-Dimensional Molecular Lay out by Means of Hydrogen Bond Formation}

Dr. M. Abel ${ }^{[\mathrm{a}]^{*}}$, Dr. V. Oison ${ }^{[\mathrm{a}]^{*}}$, M. Koudia ${ }^{[\mathrm{a}]}$, Dr. C. Maurel ${ }^{[\mathrm{a}]}$, Dr C. Katan $^{[\mathrm{b}]}$ and Prof. Dr.

L. Porte $\mathrm{e}^{[\mathrm{a}]}$

[a] L2MP, UMR6237 CNRS 6137, Université Paul Cézanne Aix-Marseille III, Case 151, 13397

Marseille Cedex 20, France

Fax: (+33) 491282859

E-mail:mathieu.abel@l2mp.fr

vincent.oison@univ-3mrs.fr

[b] SESO, UMR6510 CNRS, Université Rennes I, Campus de Beaulieu, Bât 10A, 35042, Rennes

cedex, France

Keywords : Density functional calculation, Hydrogen bonding, Molecular self-assembly, Scanning tunneling microscopy, Vacuum deposition.

Supra-molecular structures formed by the self-assembly of functional molecular building blocks are a promising class of materials for future technologies. ${ }^{[1-3]}$ Hydrogen bonding is particularly interesting for their fabrication as it provides both high selectivity and directionality. Recently, this concept was used to produce either two-dimensional or linear nanostructures at surfaces by molecular beam epitaxy. ${ }^{[4-8]}$ Herein, we show that molecular films can evolve in time towards a close-packed organization induced by the activation of an original two-dimensional hydrogen bond network, consisting in $\mathrm{H}$... Cl bonds. The combination of scanning tunneling microscopy experiments and density functional calculations was performed on Chlorine-Zinc-Phthalocyanines $\left(\mathrm{ZnPcCl}_{8}\right)$ adsorbed onto 
$\operatorname{Ag}(111)$ surface. We demonstrate that the location of chlorine atoms on phenyl rings predetermines the final two-dimensional molecular network.

The adsorption of large and flat Metal-Phthalocyanine (M-Pc) molecules is well documented on both metallic and semiconductors surfaces. ${ }^{[9-13]}$ In this class of molecules, self-assembly is governed by the subtle balance between molecule-molecule and moleculesurface interactions, which can be tuned by the modification of surrounding atoms of the phthalocyanine. ${ }^{[14]}$ A large variety of organizations at surfaces has been reported depending on the nature of the central atom and surrounding atoms. Intermolecular interactions influence the way molecules will organize on the top of a surface. They can be either electrostatic in nature, including both multi-polar static and dynamical van der Waals contributions, or arise from orbital overlap, or both. The choice of $\mathrm{ZnPcCl}_{8}$, which is obtained from the substitution of half of the sixteen surrounding hydrogen atoms of $\mathrm{ZnPc}$ by chlorine atoms (Figure 1), was motivated by the possibility of building compact molecular organization mainly governed by hydrogen bonds. These molecules are well-known electron acceptors and interactions with the metallic surface result from partial charge transfer from surface electronic states to the lowest unoccupied molecular orbital (LUMO), of $\pi$ type ${ }^{[15]}$ Thus, according to the strength of this overlap, symmetry of the host surface may more or less influence the way molecules adsorb and organize on this surface. In order to reduce the influence of the substrate on the molecular arrangement, $\mathrm{Ag}$ metal which has moderate reactivity and oxidation potential (i.e. electron donor character) appears in that sense a quite good candidate. Looking for minimal substratemolecule interaction motivated the choice for $\mathrm{Ag}(111)$ low surface energy and closed shell $\mathrm{Zn}$ $\left(4 s^{2} 3 d^{10}\right)$ as central metal.

This letter presents a combined experimental and theoretical approach on the molecular packing of $\mathrm{ZnPcCl}_{8}$ molecules deposited onto $\mathrm{Ag}(111)$ surfaces. Experiments involve room temperature scanning tunneling microscopy (STM) and theoretical calculations are based on density functional theory (DFT) within the framework of the projectoraugmented wave (PAW) method. ${ }^{[16]}$ The evolution of three different two-dimensional arrangements observed on STM images, discussed with special attention to hydrogen bonds, 
demonstrates that the driving force for the final network is directly related to the formation of $\mathrm{H}$...Cl contacts between molecules. Using the InteGriTy software package, ${ }^{[17]}$ which achieves topological analysis following Bader's approach on electron densities given on 3D grids, ${ }^{[18]}$ quantitative analysis of the main electronic contacts between molecules is investigated for all three structures. Just after the deposition of approximately $0.5 \mathrm{ML}$ of $\mathrm{ZnPcCl}_{8}$ on $\mathrm{Ag}(111)$, large domains with well organized molecules are observed on STM images. Such an organization, denoted P1, is shown on figure 2a. Natural maturation during a few hours leads to a second two-dimensional network denoted P2 and represented in figure $2 b$. Finally, ten hours after deposition, the network transforms into a third arrangement denoted P3 and shown in figure 2c. Transformation from P1 to P3 can also be achieved in few minutes through gentle annealing at $320 \mathrm{~K}$. In all cases, an individual molecule is imaged as a symmetric cross-like structure indicating that bonding to Ag surface atoms enforces a flat adsorption geometry. Moreover, two of the four molecular arms are aligned in all arrangements with one close-packed [110] direction of the Ag (111) substrate. As a consequence the two perpendicular arms of the molecule (symmetry A4) lie in-between two close-packed directions of the substrate (symmetry A3). The ripening process clearly increases the packing density: 0.33 molecule per $\mathrm{nm}^{2}$ in the initial P1 network $\left(\mathrm{a}=\mathrm{b}=1.8 \mathrm{~nm} ; \alpha=72^{\circ}\right)$, then 0.38 molecule per $\mathrm{nm}^{2}$ in the intermediate P2 network $\left(\mathrm{a}=1.8 \mathrm{~nm} ; \mathrm{b}=1.5 \mathrm{~nm} ; \alpha=75^{\circ}\right)$ and finally 0.44 molecule per $\mathrm{nm}^{2}$ in the final $\mathrm{P} 3$ network $\left(\mathrm{a}=\mathrm{b}=1.5 \mathrm{~nm} ; \alpha=89^{\circ}\right)$.

During $\mathrm{P} 1$ to $\mathrm{P} 2$ transformation, $\mathrm{ZnPcCl}_{8}$ molecules moved as to join the first two opposite arms. The two other arms join during P2 to P3 transformation leading to the maximum compactness. However, P3 structure evidences also faulty lines reminiscent of P2. We failed in attempts we did to eliminate these faulty lines to realize full layer completion. Most probably, faulty lines participate to the stabilization of P3 network. In this letter, we intend to focus on the role of hydrogen bonding on the self-organization of $\mathrm{Zn}$ - $\mathrm{Pc}$ molecules and will not comment further on the role of such defect lines.

An enlargement of each domain is represented on the right side of figure 2. In these representations a drawing of the unit cell and a representation of rigid $\mathrm{ZnPcCl}_{8}$ is superposed 
to STM images. Changing from P1 to P2, and then to P3 structure, molecules have moved in order to approach hydrogen atoms of one molecule towards $\mathrm{Cl}$ atoms of neighboring molecules, leading to the formation of $\mathrm{H}$...Cl contacts. The role of hydrogen bonding on the molecular organization has been quantified by DFT calculations, taking experimental lattice parameters. The calculated molecular cohesive energy of the first 2D-arrangement (P1) is found to be $5.2 \mathrm{~kJ}$ per mole. The topological analysis of the theoretical electron density reveals that intermolecular contacts in this phase are very weak: as shown in figure 3a, no significant electronic overlap between molecules is evidenced. The shortest intermolecular distances $(0.45 \mathrm{~nm}$ and $0.51 \mathrm{~nm})$ correspond to the distances between two neighboring $\mathrm{Cl}$ atoms. Thus, intermolecular cohesive energy is mainly due to static multi-polar and dynamical van der Waals interactions. Similar interactions have been reported for other M-Pc molecule films deposited on metallic surfaces. ${ }^{[9-11]}$

The calculated molecular cohesive energies for P2 and P3 structures are respectively 12.5 and $16.4 \mathrm{~kJ}$ per mole. The different intermolecular electronic contacts involved in these molecular organizations are represented in figure 3. Calculation shows that contacts between the molecules are limited to the $\mathrm{H} . . . \mathrm{Cl}$ and $\mathrm{Cl}$... Cl contacts. From P1 to P3 the number of $\mathrm{H}$... Cl contacts increases. In particular, $\mathrm{H}$... Cl contacts which are lacking in P1 involve four out of eight hydrogen atoms in P2, and all eight hydrogen atoms in the final network P3. For this later structure, characteristics of the different critical points (CP) corresponding to intermolecular bonds are reported in Table1.

The values of electron $n\left(\boldsymbol{r}_{C P}\right)$ and potential energy $V\left(\boldsymbol{r}_{C P}\right)$ densities at the critical point can be used to gauge the relative strength of the different electronic contacts. Half of the $\mathrm{Cl}$ atoms are involved in the strongest $\mathrm{H}$... Cl contacts among which two groups can be distinguished: $\mathrm{H}(1) \ldots \mathrm{Cl}$ and $\mathrm{H}(2) \ldots \mathrm{Cl}$. As shown in figure $3 \mathrm{c}$, each molecule is connected to its neighbors by four $\mathrm{H}(1) \ldots \mathrm{Cl}$ and four $\mathrm{H}(2) \ldots \mathrm{Cl}$ contacts. The corresponding bond lengths 0.269 and $0.277 \mathrm{~nm}$ for $\mathrm{H}(1) \ldots \mathrm{Cl}$ and $\mathrm{H}(2) \ldots \mathrm{Cl}$ respectively are significantly shorter than the sum of the van der Waals atomic radii: $\mathrm{r}_{\mathrm{H}}+\mathrm{r}_{\mathrm{Cl}}=0.294 \mathrm{~nm} .{ }^{[21]}$ The $\mathrm{H}(1) \ldots \mathrm{Cl}$ contacts are slightly stronger than the $\mathrm{H}(2) \ldots \mathrm{Cl}$ ones as both $\mathrm{n}\left(\mathbf{r}_{\mathrm{CP}}\right)$ and $\mathrm{V}\left(\mathbf{r}_{\mathrm{CP}}\right)$ are about 30 percent larger. 
This $\mathrm{H}$...Cl bonding involves not only dynamical interaction but also static multipolar interactions and overlap between $\mathrm{H}$ and $\mathrm{Cl}$ atoms, usually not observed in the case of classical van der Waals bonding. In addition, previous experimental and theoretical topological studies of intermolecular contacts in other organic compounds reported similar topological characteristics for $\mathrm{C}=\mathrm{O} \ldots \mathrm{H}-\mathrm{C}$ hydrogen bonds. ${ }^{[19,20]}$ Hence, the $\mathrm{H} . . \mathrm{Cl}$ contacts evidenced here can be considered as hydrogen bonds. As shown in table 1 weak $\mathrm{Cl}$... Cl intermolecular contacts involving the four remaining $\mathrm{Cl}$ atoms also contribute in the cohesion of the molecular packing.

In the calculations discussed above, interactions between molecule and substrate were not explicitly taken into account. ${ }^{[22]}$ Due to orbital overlap, partial electron transfer from the electron releasing $\mathrm{Ag}$ surface towards the electron withdrawing $\mathrm{ZnPcCl}_{8}$ molecule should be considered. This will influence the strength of the $\mathrm{H} . . \mathrm{Cl}$ bonds as well as the calculated cohesive energy that is here only indicative. To gain some insight into the effect of such a charge transfer, we investigated the $\mathrm{ZnPcCl}_{8}$ molecule having an additional electron in its LUMO. The resulting electronic redistribution mainly affects the $\mathrm{Cl}$ atoms, which become more negatively charged. This should lead to an enhancement of the $\mathrm{H}$...Cl bonds via the coupling between charge transfer and strength of hydrogen bonds. ${ }^{[23]}$

This present joint theoretical and experimental investigation has revealed how the twodimensional arrangement of molecules can be governed by their functional atoms. In the case of $\mathrm{ZnPcCl}_{8}$ deposited on the relative neutral $\mathrm{Ag}(111)$ surface, the final organization is driven by the activation of an original hydrogen bond network consisting on $\mathrm{H}$...Cl electronic contacts. This activation occurs either in minute time after a gentle annealing at $320 \mathrm{~K}$ or after ten hours at room temperature. Thus, the structure kinetics can be described as follows: the two-dimensional arrangement of $\mathrm{ZnPcCl}_{8}$ observed just after deposit seems to minimize the interactions between molecules and the $\operatorname{Ag}(111)$ surface. Consequently, the molecules are aligned along the close-packed direction of the substrate. The topology of the corresponding electron density indicates that the main contribution to the intermolecular cohesive energy results from weak interactions without significant overlap between molecules. This first two- 
dimensional arrangement is meta-stable, and structural re-arrangement follows in two steps. Activation of half of possible hydrogen bonds (i.e. four out of eight) leads to an intermediate network in a couple of hours. This induces a contraction of one of the lattice parameter and a gain in intermolecular cohesive energy. In a second step, the four remaining hydrogen bonds are activated as well leading to the final two-dimensional organization with additional gain in intermolecular cohesive. To summarize, we demonstrate that the final molecular packing onto surface is pre-determined by the location of substitution chlorine atoms on phenyl rings. Thus, molecular synthesis techniques allow choosing the suitable location of functional groups in order to design a large variety of two-dimensional molecular networks. This strategy allows the design of new surface structures and materials for future applications.

\section{Experimental and computational Section}

Sample preparation: Small amounts of $\mathrm{ZnPcCl}_{8}$ were evaporated under ultra-high vacuum conditions $\left(10^{-10}\right.$ mbar) onto $\mathrm{Ag}(111)$ surface. The $\mathrm{Ag}(111)$ surface was prepared by repeated cycles of argon sputtering $(2.5 \mathrm{keV}, 1 \mu \mathrm{A})$ followed by annealing at $720 \mathrm{~K}$. $\mathrm{ZnPcCl}_{8}$ molecules were first outgassed in vacuum, then evaporated from an effusion cell onto the substrate kept at room temperature. The deposition rate was about 0.30 mono-layers per minute. (One monolayer corresponds to a complete layer of the dense molecular phase).

Scanning tunneling microscopy: Images were recorded the VT-STM (Omicron) using tungsten etched tips. All experiments were performed at room temperature with tunnelling conditions in the range $I=0.2 n A$ and $V($ tip $)=-1.2 \mathrm{~V}$.

Computational details: All calculations have been performed within the framework of density functional theory (DFT) using the generalized gradient approximation (GGA) parametrization by Perdew-Burke-Ernzehoff for the exchange correlation energy. ${ }^{[24]}$ We used the projector-augmented wave (PAW) method, ${ }^{[16]}$ which uses augmented plane waves in order to describe the full wave functions and densities without shape approximation. Core electrons were treated within the frozen core approximation. Band structure calculation has been carried out with a plane wave cutoff of $30 \mathrm{Ry}$. All calculations have been performed at constant lattice parameters deduced from experiments. 
Atomic positions were relaxed using the original fictitious Lagrangian approach of Car and Parrinello. ${ }^{[25]}$ In our simulations, the interactions between molecules and surface have been neglected. The topological analysis was performed using the InteGriTy software package, ${ }^{[17]}$ which achieves topological analysis following Bader's approach on electron densities given on $3 \mathrm{D}$ grids. ${ }^{[18]}$

\section{Acknowledgements}

The authors would like to thank M. and J.C. Mossoyan for the synthesis of the $\mathrm{ZnPcCl}$ molecules, A. Bliek and D. Catalin for experimental assistance. They gratefully acknowledge P.E. Blöchl for sharing his PAW code. Calculations have been supported by 'Centre Informatique National de l'Enseignement Supérieur' (CINES-France).

[1] J.M. Lehn, Science 1993, 260, 1762.

[2] N. Bowden, A. Terfort, J. Carbeck, G.M. Whitesides, Science 1997, 276, 233.

[3] C. Joachim, J.K. Gimzewski, A. Aviram, Nature 2000, 408, 541.

[4] D. Philp, J.F. Stoddart, Angew. Chem. Int. Ed 1996, 35, 1155.

[5] J.A. Theobal, N.S. Oxtoby, M.A. Philips, N.R. Champness, P.H. Beton, Nature 2003, 424, 1029.

[6] J.V. Barth, J. Weckesser, N. Lin, A. Dmitriev, K. Kern, Appl. Phys. A 2003, 76, 645.

[7] A. Dmitriev, N. Lin, J. Weckesser, J.V. Barth, K. Kern, J. Phys. Chem B 2002, 106, 6907.

[8] J.V. Barth, J. Weckesser, C. Cai, P. Günter, L. Bürgi, O. Jeandupeux, K. Kern, Angew. Chem. 2000, 112, 1285, Angew. Chem. Int. Ed. 2000, 39, 1230.

[9] X. Lu, K.W. Hipps, J. Phys. Chem. B 1997, 101,5391. 
[10] X. Lu, K.W. Hipps, X.D. Wang, U. Mazur, J. Am. Chem. Soc. 1996, 118, 7197.

[11] J.Y. Grand, T. Kunstmann, D. Hoffmann, A. Haas, M. Dietsch, J. Seifritz, R. Moller, Surf. Sci. 1996, 366, 403.

[12] M. Kanai, T. Kawai, K. Motai, X.D. Wang, T. Hashizume,T. Sakura, Surf. Sci. 1995, $329,619$.

[13]S. Yim, T.S. Jones, Q. Chen, N.V. Richardson, Phys. Rev. B 2004, 69, 235402.

[14] Z.Y. Yang, S.B. Lei, L.H. Gan, L.J. Wan, W. Chen, C.L. Bai Chem. Phys. Lett. 2005, 6, 65.

[15] M.S. Liao, S. Scheiner, J. Chem. Phys. 2000, 114, 9780.

[16] P.E. Blöchl, Phys. Rev. B 1994, 50, 17953.

[17] C. Katan, P. Rabiller, C. Lecomte, M. Guezo, V. Oison, M. Souhassou, J. Appl. Crystallogr. 2003, 36, 65.

[18] R.F.W. Bader, Atoms in Molecules: A quantum theory, The International Series of Monographs on Chemistry, Clarendon Press, Oxford, 1990.

[19] E. Espinosa, E. Molins, C. Lecomte, Chem. Phys. Lett. 1998, 285, 170.

[20] V. Oison, P. Rabiller, C. Katan, J. Phys. Chem. A 2004, 108, 11049.

[21] A. Bondi, J. Phys. Chem. 1964, 68, 441.

[22] Note: they are partially included as they influence the parameters of the two-dimensional molecular packing that have been fixed at experimental values in all of calculations.

[23] V. Oison, C. Katan, C. Koenig, J. Phys. Chem. A 2001, 17, 4300.

[24] J.P. Perdew, K. Burke, M. Ernzerhof, Phys. Rev. Lett. 1996, 77, 3865.

[25] R. Car, M. Parrinello, Phys. Rev. Lett. 1985, 55, 2471. 
Received: ((will be filled in by the editorial staff))

Published online on ((will be filled in by the editorial staff))

Figure 1: Optimized $D_{4 h}$ structure of $\mathrm{ZnPcCl}_{8}$ obtained from DFT calculation on isolated molecules.

Figure 2: STM images of the three two-dimensional arrangements of $\mathrm{ZnPcCl}_{8}$ molecules on $\operatorname{Ag}(111)$ obtained at room temperature: (a) immediately after the deposit (P1 phase); (b) few hours later (intermediate P2 phase) and (c) after ten hours (final P3 phase). In the right column, models for the molecular superstructures are given for each phase. $\mathrm{ZnPcCl}_{8}$ molecules are unrelaxed and drawn to scale on top of STM images. Chlorine atoms are represented by green spheres in position 3,4 of phenyl rings whereas $\mathrm{H}$ are in position trans 2,5 .

Figure 3: Electron isodensity curves in molecular plane for P1, P2 and P3 arrangements, respectively shown on top, middle and bottom. The electron density values correspond to 0.040 (grey curve) and $0.540 \mathrm{e}^{-}$per $\AA^{3}$ (black curve). For clarity, $\mathrm{H}(1) \ldots \mathrm{Cl}$ and $\mathrm{H}(2) \ldots \mathrm{Cl}$ electronic contacts are represented by large black segments . 
Table 1: Strongest intermolecular contacts of the $\mathrm{P} 3$ phase. $\mathrm{n}\left(\mathbf{r}_{\mathrm{CP}}\right)$ and $\mathrm{V}\left(\mathbf{r}_{\mathrm{CP}}\right)$ correspond respectively to the values of the electron density in $\mathrm{e}^{-} \AA^{-3}$ and the potential energy density in $\mathrm{kJ}$ $\mathrm{mol}^{-1}$ at the bond critical point (CP). The distance $\mathrm{d}$ corresponds to intermolecular bond length in $\mathrm{nm}$ between $\mathrm{H} . . \mathrm{Cl}$ or $\mathrm{Cl}$... $\mathrm{Cl}$ atoms.

\begin{tabular}{llll} 
Contact & $\mathrm{n}\left(\mathbf{r}_{\mathrm{CP}}\right)$ & $\mathrm{V}\left(\mathbf{r}_{\mathrm{CP}}\right)$ & $\mathrm{d}(\mathrm{nm})$ \\
\hline $\mathrm{H}(1) \ldots \mathrm{Cl}$ & 0.064 & -12.20 & 0.269 \\
$\mathrm{H}(2) \ldots \mathrm{Cl}$ & 0.048 & -9.06 & 0.277 \\
$\mathrm{Cl} \ldots \mathrm{Cl}$ & 0.030 & -4.90 & 0.373
\end{tabular}

Suggestion for the table-of-contents: The substitution of surrounding $\mathrm{H}$ atoms of phthalocyanine by chlorine atoms determines the formation of molecular self-assembly at surfaces. The structure obtained after deposition (see picture) is induced by the activation of an original two-dimensional hydrogen bond network, consisting in $\mathrm{H}$... Cl bonds between neighboring molecules.

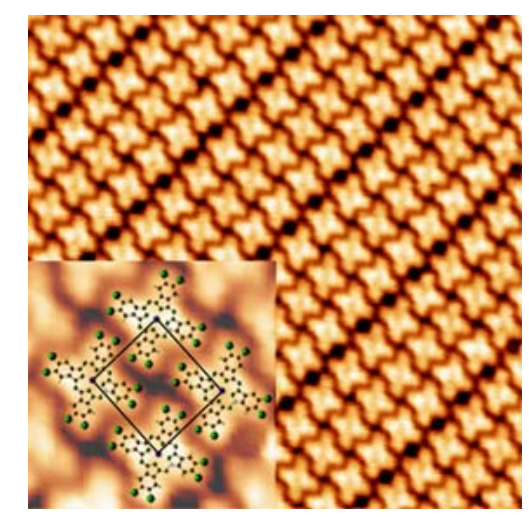




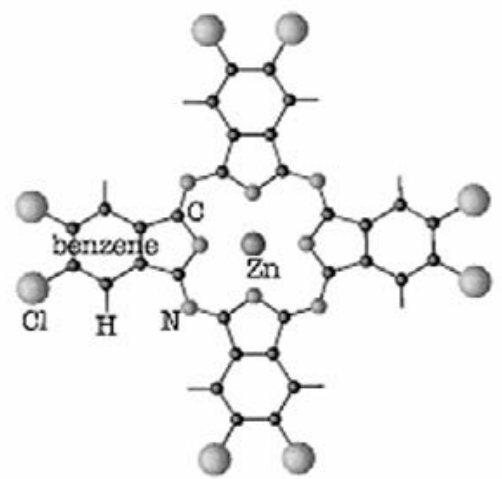

Figure 1 


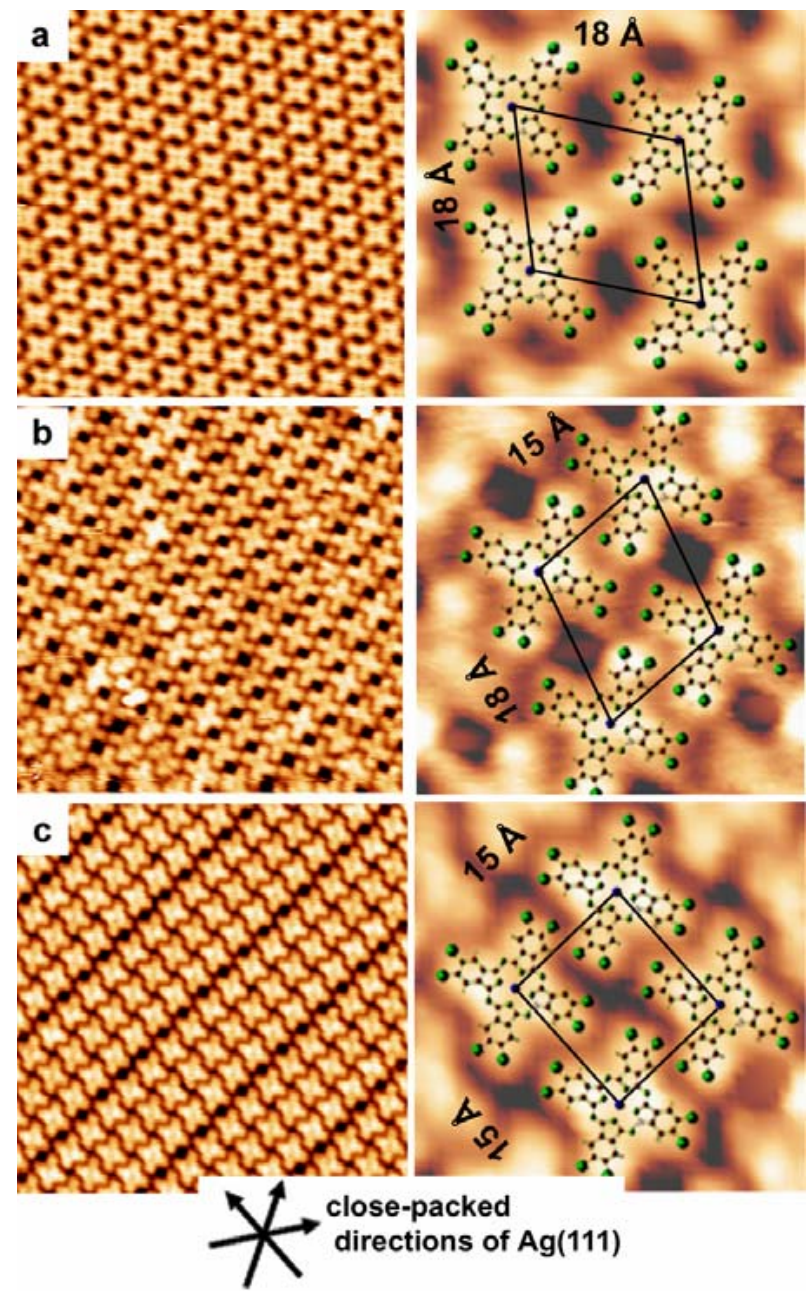

Figure 2 

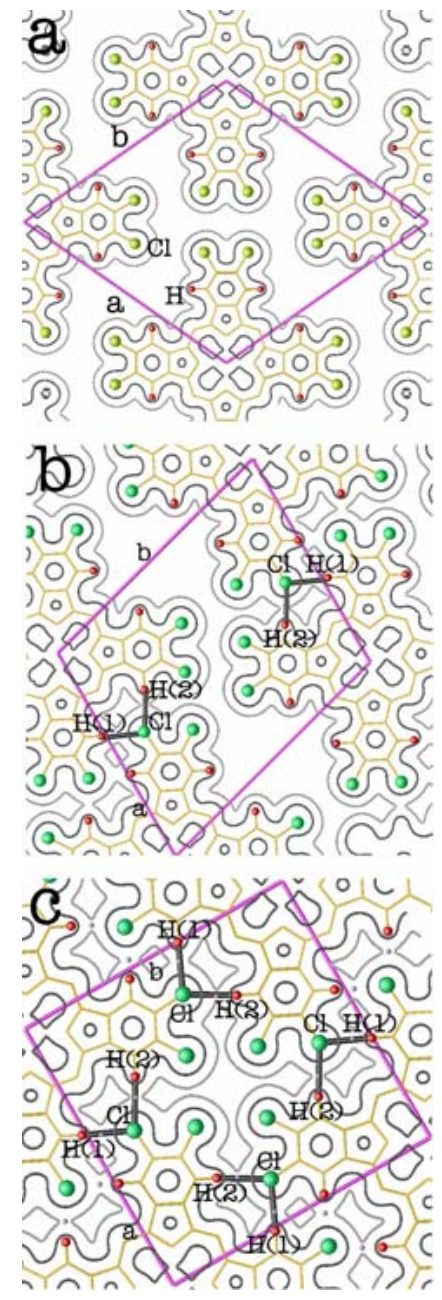

Figure 3 